\title{
The Profile of Infantile Hypertrophic Pyloric Stenosis in a Tertiary Children's Hospital in Nepal
}

\section{Bal Mukunda Basnet, Robal Lacoul, Raj Kumar Singh, Prashant Simkhada and Gajendra Chaudhary}

Department of Paediatric Surgery, Kanti Children's Hospital, Maharajgunj, Kathmandu, Nepal

\author{
Correspondence: \\ Robal Lacoul \\ Department of Paediatric Surgery, \\ Kanti Children's Hospital, Maharajgunj, \\ Kathmandu, Nepal \\ Email:drlacoul@gmail.com
}

DOI: $10.3126 /$ jnps.v41i2.35001

Submitted on: 2020-06-11

Accepted on: 2020-10-04

Acknowledgements: None

Funding: Nil

Conflict of Interest: None declared

Permission from IRB: Yes

To cite this article: Basnet BM, Lacoul R, Singh RK, Simkhada P, Chaudhary G. Profile Of Infantile Hypertrophic Pyloric Stenosis In A Tertiary Children's Hospital In Nepal. J Nepal Paediatr Soc. 2021;41(2):253-7.

\section{ABSTRACT}

Introduction: Infantile Hypertrophic Pyloric Stenosis (IHPS) is the most common surgical cause of non-bilious vomiting in infancy and in the developed world. It is more common among male infants with a peak age at presentation of 4 weeks. This study aims to review the mean age at the time of diagnosis, serum electrolyte changes, ultrasonographic pyloric dimensions and surgical outcomes in IHPS at a tertiary children's hospital in Nepal.

Methods: A retrospective chart review of patients with IHPS who presented to Kanti Children's Hospital between June 2016 and June 2020 was performed. Data on age, sex, laboratory and ultrasonographic dimensions, treatment and outcomes of treatment were collected and analysed.

Results: The clinical record of 150 infants were retrieved and analysed who were diagnosed according to the clinical manifestations, laboratory and ultrasound examination from 2016 to 2020 . The mean age at presentation was $46.57 \pm 27.3$ days with male preponderance of $84 \%$. The proportion of IHPS cases with hyponatremia and hypokalemia was $31.3 \%$ and $18.0 \%$ respectively. The mean pyloric muscle thickness and pyloric length was $5.4 \mathrm{~mm}$ and $20.28 \mathrm{~mm}$ respectively. All cases were managed with Ramstedt pyloromyotomy with an average length of hospital stay of 5.03 days. There was no mortality and also no significant major complications.

Conclusions: This study has shown that IHPS is a common condition in our setting. More attention should be paid to diagnose early. Paediatricians and general surgeons should have high index of suspicion in infants with non-bilious vomiting to avoid delay in diagnosis.

Keywords: Infantile hypertrophic pyloric stenosis; Mean Age; Nepal

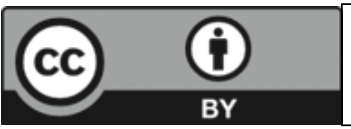

This work is licensed under creative common attribution 3.0 license 


\section{INTRODUCTION}

Infantile Hypertrophic Pyloric Stenosis (IHPS) is caused by circular muscular hypertrophy at the pylorus causing incomplete gastric outlet obstruction. The incidence of IHPS is $2-4 / 1000$ live births in Western populations but is much lower (1/ 1000 live births) in African and Asian populations. ${ }^{1}$ It is more common among male infants with a male to female sex ratio estimated at 4-6:1. ${ }^{2}$ Ninety-five percent of cases of IHPS present between the third and $12^{\text {th }}$ week of life, with a peak age at presentation of four weeks. ${ }^{3,4}$ This condition accounts for one third of non-bilious vomiting occurrences in infants and is the commonest surgical cause of non-bilious vomiting and the reason for laparotomy before one year of age. ${ }^{1,5}$

Several studies have shown that the classic electrolyte abnormalities of hypochloremic, hypokalemic, metabolic alkalosis is present in less than $50 \%$ of the patients with pyloric stenosis. ${ }^{6}$ The etiology of IHPS remains unknown, existing evidence suggests that environmental and genetic factors might contribute to the development of this disease. ${ }^{7}$ Ultrasound is the most accepted and used method in diagnosing IHPS, especially when combined with the history of projectile emesis and the hypochloremic metabolic alkalosis. ${ }^{6}$ Pyloromyotomy is considered to be an effective treatment for IHPS and the complication rates vary between 4.6 and $12 \%{ }^{6}$

The aim of this study was to review the demographic patterns, serum electrolyte changes as well as ultrasonographic pyloric dimensions and surgical outcomes in patients with IHPS and to compare our findings with studies in other parts of the world.

\section{METHODS}

A retrospective study was carried out at Kanti Children's Hospital, Kathmandu, Nepal from June 2016 - June 2020. The diagnosis of IHPS was made clinically by the typical clinical presentation of non-bilious vomiting, gastric peristalsis, palpable pyloric tumour and by abdominal ultrasound on which IHPS is characterised by increased pyloric muscle thickness $\geq 3 \mathrm{~mm}$ and pyloric channel length $15 \mathrm{~mm}$ or greater. ${ }^{8}$ The study was approved by the Medical Ethics Committee of Kanti
Children's Hospital. The sample size was calculated according to the article "Hypertrophic pyloric stenosis in the Third World, Tropical Doctor", where SD of the mean age of neonate at presentation of IHPS was 2.6 weeks $^{1}$ and sample size of 141 was calculated. Data were extracted from the medical records division of this hospital. The following information was collected: gender, age at diagnosis, weight, length of hospital stay, electrolyte levels at presentation (serum sodium and serum potassium), ultrasonographic data (pyloric muscle thickness and pyloric length), treatment and outcomes. All analyses were performed on SPSS version 20. Mean and standard deviations was determined for continuous variables whereas proportions and frequency tables was used to summarise categorical variables.

\section{RESULTS}

Over the study period, clinical data of 150 cases of IHPS were retrieved who were confirmed using abdominal ultrasound. Among them 84\% were male, resulting in a male: female ratio of 5.25:1. The mean age at the time of presentation and diagnosis was $46.57 \pm 27.31$ days (range: seven 190 days) and the mean weight of the infant at diagnosis was $3.7 \pm 0.82 \mathrm{~kg}$ (range: $1.8-6.0 \mathrm{~kg}$ ).

Non-bilious vomiting was the most common initial symptom and in all the infants the ultrasonic findings were diagnostic of IHPS. The mean length of pyloric muscle was $20.28 \pm 3.65 \mathrm{~mm}$ (Range $14.7-29 \mathrm{~mm}$ ), and the mean thickness of pyloric circular muscle was $5.4 \pm 0.99 \mathrm{~mm}$ (Range $3.5-$ $7.5 \mathrm{~mm})$.

On admission, mean concentration of serum sodium was $136.5 \pm 5.67 \mathrm{mmol} / \mathrm{L}$ and that of potassium was $4.3 \pm 0.85 \mathrm{mmol} / \mathrm{L}$. Hyponatraemia $(<135 \mathrm{mmol} / \mathrm{L})$ and hypokalemia $(<3.5 \mathrm{mmol} / \mathrm{L})$ were observed in $31.3 \%$ and $18.0 \%$ of cases respectively. The mean duration of time taken for the dehydration and electrolyte imbalance to be corrected before the surgery was 1.61 days (range of one to 12 days). All the cases had undergone open pyloromyotomy through a transverse right upper quadrant incision. Due to lack of facility at our centre, laparoscopic pyloromyotomy modality 
Table 1. General Data of IHPS $(n=25)$

\begin{tabular}{lrr} 
Variables & \multicolumn{1}{c}{ Mean } & \multicolumn{1}{c}{ SD } \\
\hline Age at presentation (in days) & 46.57 & 27.310 \\
Gender & Male (84\%) & \\
Weight (in kg) & 3.7 & 0.82 \\
Sodium & 136.54 & 5.67 \\
Hyponatremia & $31.3 \%$ & \\
Potassium & 4.3 & 0.85 \\
Hypokalemia & $18.0 \%$ & \\
Length of hospital stay (LOS, & 5.03 & 2.2 \\
In days) & & \\
Pyloric length (in mm) & 20.28 & 3.65 \\
Pyloric Thickness (in mm) & 5.4 & 0.99 \\
\hline
\end{tabular}

of surgery was not used. The mean duration of hospital stay was $5.03 \pm 2.2$ days (range of two to 14 days). There was no surgical site infection following the surgery and no other significant major complications. There was no mortality in the study population.

\section{DISCUSSION}

IHPS is a common abdominal surgical disorder in infants and has been reported to be the most common cause of gastric outlet obstruction in infancy and the commonest surgical cause of vomiting. ${ }^{9}$ This study is a hospital-based analysis of 150 patients with IHPS in Kanti Children's Hospital of Nepal who were diagnosed according to clinical manifestations, laboratory and ultrasound examination from 2016 to 2020 . In this study, $84 \%$ of the patients were male, the male-to-female ratio was 5.25:1 which is comparable to the global ratio of $4: 1-6: 1 .^{10}$ The weight at presentation was 3.7 $\mathrm{kg}$ which is comparable with $3.78 \pm 0.69 \mathrm{~kg}$ of Li Jing et al. ${ }^{7}, 3.850 .89 \mathrm{~kg}$ of Feng et al. ${ }^{11}$

The mean age at presentation was 46.57 days in our study which is higher than a mean age of $26.5 \pm$ 26.6 days of Feng et al., 34 days of Li Jing et al. and $40.18,11.68$ days of Singh et al. ${ }^{7,11,12}$ and comparable to $49.16 \pm 21.4$ days recorded by Ezomike et al. ${ }^{13}$ This delayed presentation is a common phenomenon in developing countries which may be due to lack of awareness in families who consider vomiting as a normal physiological response and ignore it. It can also be due to prior visits to peripheral hospitals before presenting to a tertiary care centre. Therefore, it is necessary to

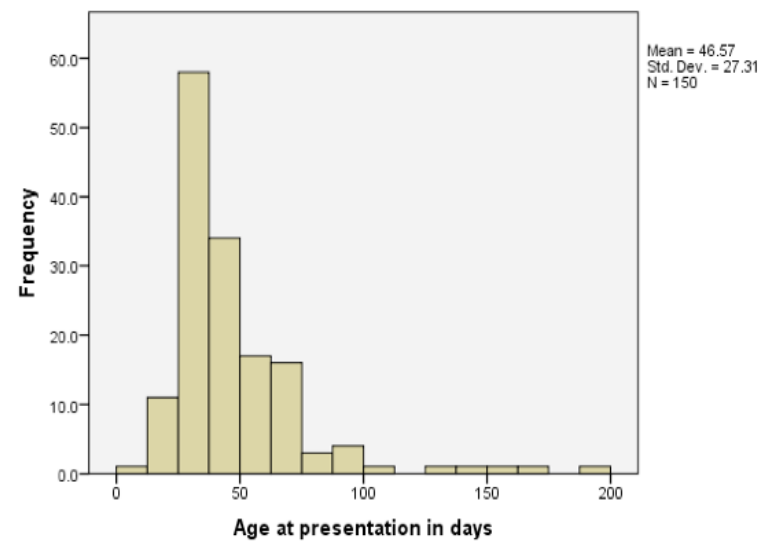

Figure 1. Age distribution at presentation

raise awareness in young parents about IHPS to avoid delay in diagnosis.

Electrolyte changes were variable showing both normal and abnormal levels. Hyponatremia was recorded in $31.3 \%$ and hypokalemia in $18 \%$ which was less in frequency as compared to other studies. ${ }^{12,13}$ This could be due to the presentation of such cases to other centres prior to referral to our center, where the electrolyte imbalance had been corrected. Analysis regarding acid-base, chloride and bicarbonate levels was not done due to lack of ABG machine at our centre.

Ultrasonography is a simple, reliable and noninvasive technique in diagnosis of IHPS. ${ }^{3}$ In our study, ultrasonography was done in all the patients and ultrasound findings were confirmed pre operatively. According to Hernanz - Schulman, the circular muscle thickness ranged from 3.3 to 7.0 $\mathrm{mm}$, and the mean was $4.660 .7 \mathrm{~mm} .{ }^{14}$ In our study, the thickness varied between 3.5 and 7.5 $\mathrm{mm}$, with the mean of $5.41 \mathrm{~mm}$, and the mean length of the pyloric channel length was $20.28 \mathrm{~mm}$ against the findings of Feng et al. in which pyloric channel length was $20.8-3.8 \mathrm{~mm}$ and muscle thickness was $5.4 \pm 1.0 \mathrm{~mm}$ against $\mathrm{Li}$ Jing et al. in which pyloric channel length was $19.4 \pm 2.5 \mathrm{~mm}$ and muscle thickness was $4.8 \pm 0.7 \mathrm{~mm}$, Singh et al. in which pyloric channel length was 19.181 .99 $\mathrm{mm}$ and muscle thickness was $5.020 .82 \mathrm{~mm} .{ }^{7,11,12}$

All had open pyloromyotomy through a transverse right upper quadrant incision. Facility of laparoscopic pyloromyotomy was absent in this centre and thus was not possible. Non-operative 
management with the use of atropine sulphate was not employed in the patient management.

The mean overall length of hospital stay in our study was 5.03 days which was comparable to Saula et al. 5.1 days $^{1}$ and less than few studies 9.45 days in Ezomike et al., 6 days in Li Jing et al.,13 but more than few studies by Singh et al and Taylor et al where the duration was 3.36 days and 4.3 days respectively. ${ }^{12,15}$ It was mainly due to late presentation to our centre with more time required for full resuscitation before surgery. It took an average of 1.61 days from admission to surgery with a mean postoperative hospital stay of 3.43 days. However, there was no mortality and no significant major complications.

The potential limitation of this study is the fact that it lacked external validity and the information about some patients was incomplete in view of the retrospective nature of the study. This might have introduced some bias in our findings. Poor documentation of data leading to exclusion of many patients was another limitation in our study. Similarly, absence of data on several risk factors reported for IHPS like birth order, maternal smoking, use of macrolides, seasonal variation were other some of the limitations. However, despite these limitations, findings from this study provide data that can be utilized to improve the care of patients with IHPS in our local setting.

\section{CONCLUSIONS}

IHPS is a common pediatric surgical condition. Fluid and electrolyte loss should be corrected before surgical intervention to reduce perioperative complications. Therefore, paediatricians and surgeons should be familiar with this condition and have high index of suspicion in infants with nonbilious vomiting in order to avoid delay in diagnosis and prompt management at regional levels.

\section{REFERENCES}

1. Saula PW, Hadley GP. Hypertrophic pyloric stenosis in the third world. Trop Doct. 2011 Oct;41(4):204-10. DOI: 10.1258/td.2011.110145. PMID: 21914675.

2. Ndongo R, Tolefac PN, Tambo FFM, Abanda MH, Ngowe MN, Fola O, et al. Infantile hypertrophic pyloric stenosis: a 4-year experience from two tertiary care centres in Cameroon. BMC Res Notes. 2018 Jan 16;11(1):33. DOI: $10.1186 / \mathrm{s} 13104-018-3131-1$.

3. Hernanz-Schulman M, Berch BR, Neblett WW. Imaging of Infantile Hypertrophic Pyloric Stenosis (IHPS). In: Medina LS, Applegate KE, Blackmore CC (eds), Evidence-Based Imaging in Pediatrics. Springer, New York, NY, 2010;447-57.

4. Vermes G, Mátrai Á, Czeizel AE, Ács N. Birth outcomes of male and female patients with infantile hypertrophic pyloric stenosis--a population-based case-control study. J Matern Fetal Neonatal Med. 2016;29(11):1777-82. DOI: 10.3109/14767058.2015.1063606. PMID: 26135791.

5. Georgoula C, Gardiner M. Pyloric stenosis a 100 years after Ramstedt. Arch Dis Child. 2012 Aug;97(8):741-5. DOI: 10.1136/archdischild-2011-301526. PMID: 22685043.

6. Peters B, Oomen MW, Bakx R, Benninga MA. Advances in infantile hypertrophic pyloric stenosis. Expert Rev Gastroenterol Hepatol. 2014 Jul;8(5):533-41. DOI: 10.1586/17474124.2014.903799. Epub 2014 Apr 10. PMID: 24716658.

7. Li J, Gao W, Zhu JM, Zuo W, Liu X. Epidemiological and clinical characteristics of 304 patients with infantile hypertrophic pyloric stenosis in Anhui Province of East China, 2012-2015. J Matern Fetal Neonatal Med. 2018 Oct; 31(20):2742-2747. DOI: 10.1080/14767058.2017.1355361.

8. Hernanz-Schulman M. Infantile hypertrophic pyloric stenosis. Radiology. 2003 May;227(2):319-31. DOI: 10.1148/ radiol.2272011329. 
9. Chalya PL, Manyama M, Kayange NM, Mabula JB, Massenga A. Infantile hypertrophic pyloric stenosis at a tertiary care hospital in Tanzania: a surgical experience with 102 patients over a 5-year period. BMC Res Notes. 2015 Nov 18;8:690. DOI: 10.1186/s13104-015-1660-4.

10. To T, Wajja A, Wales PW, Langer JC. Population demographic indicators associated with incidence of pyloric stenosis. Arch Pediatr Adolesc Med. 2005 Jun;159(6):520-5. DOI: 10.1001/archpedi.159.6.520.

11. Feng Z, Nie Y, Zhang Y, Li Q, Xia H, Gong S, et al. The clinical features of infantile hypertrophic pyloric stenosis in Chinese Han population: analysis from 1998 to 2010. PLoS One. 2014 Feb 19;9(2):e88925. DOI: 10.1371/ journal.pone.0088925.

12. Singh IK, Singh KG, Laishram RS, Singh LC. A clinical study of infantile hypertrophic pyloric stenosis. IOSR Journal of Dental and Medical Sciences (IOSR-JDMS). 2015(Dec);14(12):16-9. DOI: 10.9790/0853-141271619

13. Ezomike UO, Ekenze SO, Amah CC, Nwankwo EP, Obianyo NE. Infantile hypertrophic pyloric stenosis - Our experience and challenges in a developing country. Afr J Paediatr Surg. 2018 Jan-Mar;15(1):26-30. DOI: 10.4103/ ajps.AJPS_51_16.

14. Hernanz-Schulman M, Sells LL, Ambrosino MM, Heller RM, Stein SM, Neblett WW. Hypertrophic pyloric stenosis in the infant without a palpable olive: accuracy of sonographic diagnosis. Radiology. 1994 Dec;193(3): 771-6. DOI: 10.1148/radiology.193.3.7972822.

15. Taylor ND, Cass DT, Holland AJ. Infantile hypertrophic pyloric stenosis: has anything changed? J Paediatr Child Health. 2013 Jan;49(1):33-7. DOI: 10.1111/jpc.12027. 